\title{
Electrospray Ionization Mass Spectrometric Analysis of Noncovalent Complexes of Hydroxypropyl- $\beta$-cyclodextrin and $\beta$-Cyclodextrin with Progesterone
}

\author{
Sanghoo Lee, Soonho Kwon, Hye-Jin Shin, Eunae Cho, Kyoung-Ryul Lee, and Seunho Jung*- \\ Department of Biomolecular Mass Spectrometrv, Seoul Medical Science Institute, Seoul 152-766. Korea \\ ${ }^{\dagger}$ Department of Bioscience and Biotechnology, Bioh folecular Informatics Center, Konkuk Lniversity, Seoul 143-701, Korea \\ E-mail: shjungiâkonkukackr \\ Received Hav 15, 2009, Accepted June 12, 2009
}

Key Wonds: Progesterone. $\beta$-Cyclodextrin. Hydroxy propyl- $\beta$-cyclodextrin, Noncovalent conplex, Electrospray ionization mass spectrometry

Progesterone (pregn-4-ene-3,20-dione) is a C-21steroid hormone involved in the female reproductive systems and embryogenesis of humans and other species and consists of four interconnected cyclic hydrocarbons (Figure la). It is also an important drug used clinically to treat advanced ovarian. breast and non-small cell lung cancers. ${ }^{1,2}$ Despite its availabilities as a dnig. very low water solubility $\left(3.79 \times 10^{-5} \mathrm{M}\right)$ of progesterone makes a limited usefulness for its use. Although several formulations such as cream. oral. intramuscular oily solutions. and water suspension injections have been developed. theirs bioavailability or patient compliances is low. As one of methods to increase the water solubility of progesterone. cyclodextrins (CDs) and their derivatives have been used as complexing agent with the hormone molecule ${ }^{3-2} \mathrm{CD}$ are cyclic oligosaccharides composed of six. seven and eight $\alpha-1.4$-linked glucose units. CDs have hydrophobic cavities within their interior and can form many complexes with a variety of biologically and pharmaceutically important substances. ${ }^{8-11}$ Among them. hy'droxypropyl- $\beta$-cy'clodextrin (HP- $\beta$-CD. Figure lb) has been reported to be a good inclusion complex agent for a formula-

(a)

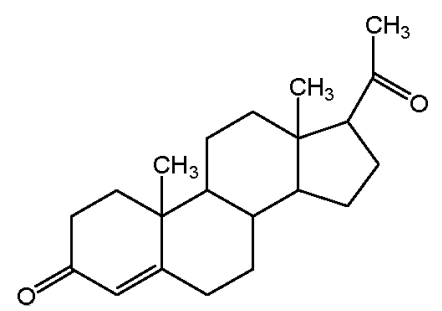

(b)

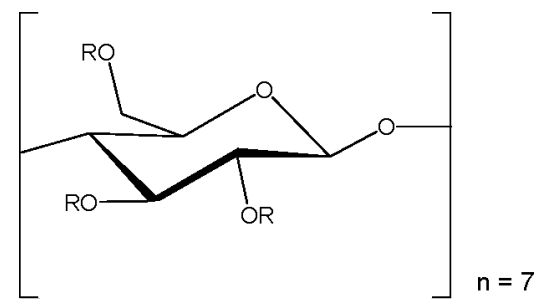

$R=H: \beta-C D$

$\mathrm{R}=\mathrm{H}$ or $\mathrm{CH}_{2} \mathrm{CH}(\mathrm{OH}) \mathrm{CH}_{3}: \mathrm{HP}-\beta-\mathrm{CD}$

Figure 1. The chemical structures of (a) progesterone and (b) $\beta$-CD and $\mathrm{HP}-\beta-\mathrm{CD}$. tion and the therapeutic dosages of progesterone by injection are up to $200 \mathrm{mg}$ depending on the specific pathology ${ }^{12} \mathrm{HP}-\beta-$ $\mathrm{CD}$. which decreases its renal toxicity. allowing parenteral administration, has higher water solubility than $\beta-\mathrm{CD}{ }^{15.14}$ The earlier studies on the inclusion complexes between progesterone and the CDs were based on solubility studies using muclear magnetic resonance (NMR). Fourier transform Infrared (FTIR) spectroscopy, differential scanning calorimetry (DSC), Raman scattering. and X-ray diffraction pattern. ${ }^{4.57}$ In contrast to to the traditional spectroscopic approaches. electrospray ionization mass spectrometry (ESI-MS) allows us to detect and identify various molecules associates between the host and the guest molecules. ${ }^{15}$ The ESI-MS is also a very useful soft ionization technique to detect the non-covalent interactions of the molecular complexes in the gas phase. ${ }^{16.17}$ No works on ESI-MS analysis of HP- $\beta$-CD- or $\beta$-CD-progesterone complexes has been therefore reported to date. In this work, we investigated stable noncovalent interactions formed between progesterone and $\beta-C D$ or $\mathrm{HP}-\beta-\mathrm{CD}$ in the gas phase using ESI-MS.

The complexes of the $\beta-C D$ or HP- $\beta-C D$ with progesterone formed in mixture of water and methanol were stable during characterization by ESI-MS. The stabilities of the complexes still remained even by applying a declustering potential as high as $120 \mathrm{eV}$. The relative abundances and the stoichiometries of the complexes formed in mixture of water and methanol can be determined in the gas phase. All the samples were observed as a nixture of the unconplexed $\beta$-CD or HP- $\beta$ $\mathrm{CD}$ and its supramolecular complexes in mass spectra. For the complex of $\beta-C D$ with progesterone, the base peak was observed at $m z \quad 1472$, which corresponds to [ $\beta-C D+$ Progesterone $+\mathrm{Na}]^{+}$ion (Figure 2). This ion indicates that the $1: 1$ complex of $\beta-C D$ with progesterone is predominant in both solution and gas phase. In addition. ions corresponding to higher ratio complexes were also observed. These higher order noncovalent complex patterns of some guest molecules with CDs or their derivatives have been often observed in supramolecular chemistry using mass spectrometry in the pattern of specific noncovalent complex ${ }^{19-3 \hat{3}}$ or nonspecific ones. ${ }^{24.26}$ Although the complex of $\beta-C D$-progesterone with stoichiometry of $1: 1$ was thermody namically characterized using differential pulse polarography. ${ }^{18}$ higher complex ratios between $\beta-C D$ and progesterone formed in mixture of 


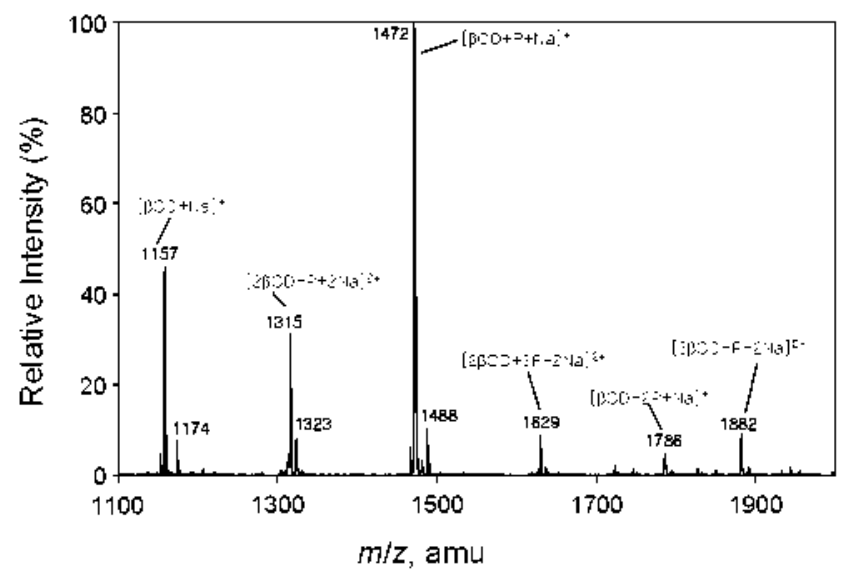

Figure 2. The ESI mass spectrum of the complex of $\beta$-CD $(2.5$ $\mathrm{mM}$ ) with progesterone $(2.5 \mathrm{~mm})$ analyzed in positive ion mode. $\mathrm{P}$ indicates progesterone

methanol and water were first detected in this study using ESI-MS. The ion at $m: 1786$ corresponds to the singly charged $1: 2$ complex $\left([\beta-\mathrm{CD}+2 \text { Progesteron }+\mathrm{Na}]^{-}\right)$between $\beta-C D$ and progesterone. Also. the doubly charged ions at $m: z$ 1315. 1629 , and 1882 correspond to the $2: 1$ ( $2 \beta-C D+$ Progesteron $\left.+2 \mathrm{Na}]^{2-}\right)$. the $2: 3\left([2 \beta-\mathrm{CD}+3 \text { Progesteron }+2 \mathrm{Na}]^{3+}\right)$. and the $3: 1\left(\left[3 \beta-\mathrm{CD}+\text { Progesteron }+2 \mathrm{Na}^{]^{++}}\right]^{+}\right)$complexes. respectively. The $1: 1$ complex of $\beta-C D$ with progesterone in the gas phase may result from specific noncovalent interaction. which was also evidenced by the thermodynamic method in the solution phase ${ }^{18}$ However the ions corresponding to the other complexes containing the $1: 2$ complex of $\beta-C D$ with progesterone may be due to nonspecific noncovalent adducts. which are often formed during the ESI-MS process. Actually. it has been reported that these nonspecific adducts are observed in the mass spectra of the complexes of CDs with amino acids or small peptides in the gas phase. ${ }^{2-2 \pi}$

In the solution phase, the $1: 1$ and $2: 1$ complexes of HP- $\beta$ $\mathrm{CD}$ with progesterone were suggested through phase solubility diagram and nuclear magnetic resonance (NMR) spectroscopic analy'sis. as described previously. ${ }^{4.5}$ In the ESI mass spectra of the conplexes of HP- $\beta-C D$ with progesterone in the gas phase. interestingly. doubly and triply charged ions showing noncovalent associations between the host and the guest were observed. but no ions corresponding to $1: 1$ complex were observed (Figure 3). Among the complex ions. the doubly charged ions at the region from $m z 2161$ to 2480 were dominant and were assigned as the $2: 4$ complex of HP- $\beta-C D$ with progesterone $\left([2 \mathrm{HP}-\beta-\mathrm{CD}+4 \text { progesterone }+\mathrm{K}]^{\hat{2}}\right)$. Also. triply charged ions corresponding to the $3: 4$ ([3HP- $\beta-C D+4$ progesterone $\left.+\mathrm{Na}+\mathrm{K}]^{3+}\right)$ complex and the $3: 5([3 \mathrm{HP}-\beta-\mathrm{CD}+5$ progesterone $+\mathrm{K}]^{3-}$ ) conplex of the host with the guest were clearly observed in the mass spectra as shown in inset of Figure 3. Although noncovlent complexes of hydroxypropylated CD derivatives with specific guest molecules such as lorazepam often yield specific noncovalent complexes of higher ratios. as evidenced by ESI mass spectra, ${ }^{19}$ these unusual higher complex ratios of HP- $\beta-C D$ with progesterone were first detected in this study. This result strongly suggests that the noncovalent complexes of HP- $\beta-C D$ with progesterone may be the anomalous nonspecific adducts formed during the ESI process rather than lydrophobic inclusion conplex.

In the present work. we first detected supramolecular entities with the higher complex ratios based on stable supramolecular noncovalent interactions between $\beta-C D$ or its HP- $\beta-C D$ and progesterone in gas phase using ESI-MS. ESI-MS could be a

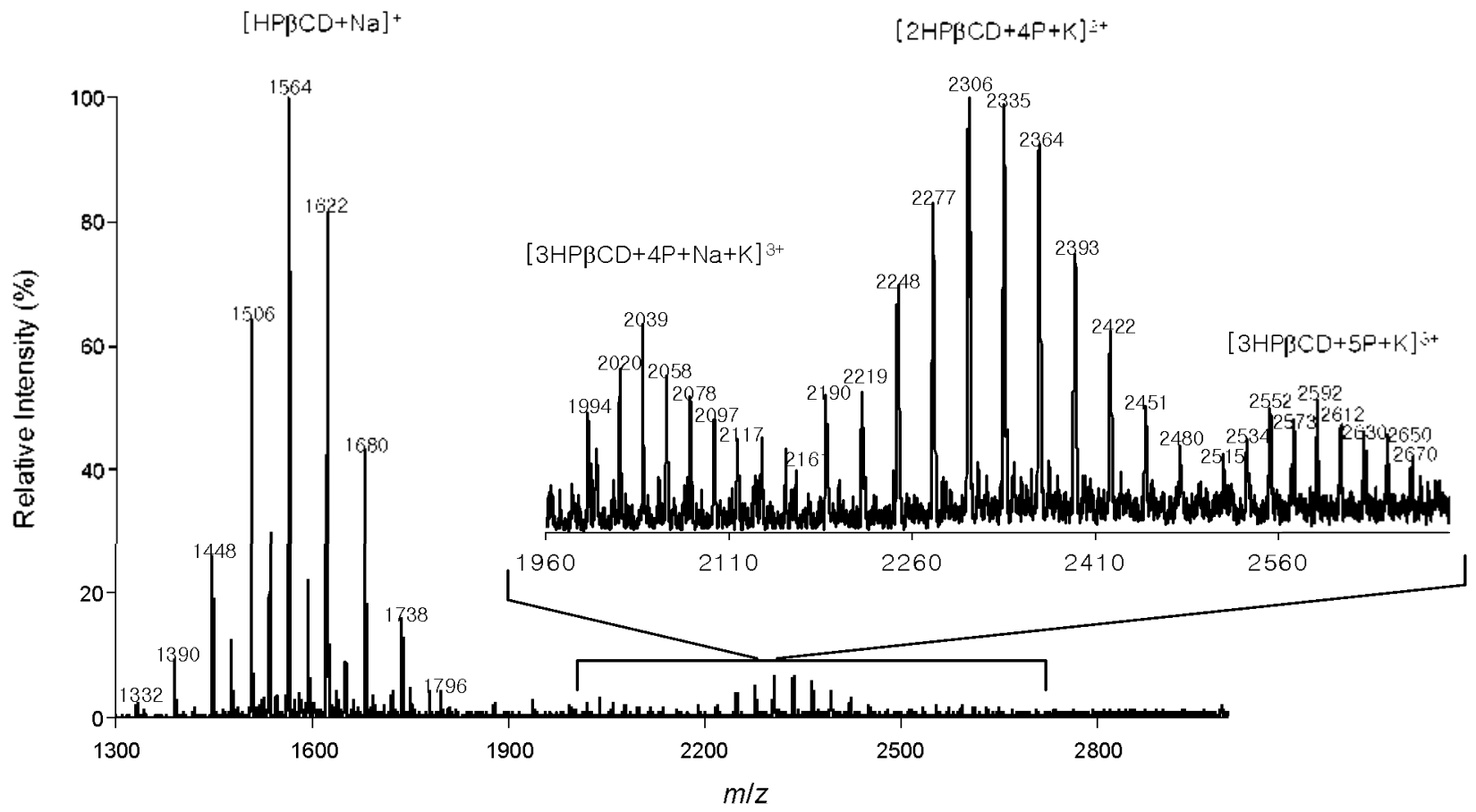

Figure 3. The ESI mass spectrum of the complex of $\mathrm{HP}-\beta-\mathrm{CD}(2.5 \mathrm{mM})$ with progesterone $(2.5 \mathrm{mM})$ analyzed in positive ion mode. 
useful analytical tool to characterize stoichiometries of the noncovalent complexes formed in mixture of water and methanol. Supramolecular host-guest stnictures based on stable noncovalent interactions between $\beta-C D$ and the homone formed in solution yielded not only $1: I$ complex but also $1: 2,2: 1,2: 3$. and 3:1 complexes. In the case of HP- $\beta-C D$. stable noncovalent interactions induced by HP- $\beta$-CD yielded doubly - and triply-charged ions in which 2:4, 3:4. and $3: 5$ complexes between the HP- $\beta-C D$ and progesterone were observed in cationized forms with $\mathrm{Na}$ and/or $\mathrm{K}$. These results suggest that nonspecific interactions may be the main driving force for the formation of the noncovalent complexes of $\beta-C D$ or HP- $\beta-C D$ with progesterone rather than hydrophobic inclusion interactions. This study will help to characterize supramolecular entities with the higher complex ratios in other steroid-CD complexes.

\section{Experimental Section}

Materials. HP- $\beta-C D, \beta-C D$, and progesterone were purchased from Sigma Chemical Co. (St. Louis, MO, USA).

Preparation of the complexes of HP- $\beta$-CD or $\beta$-CD with progesterone. A stock solution of progesterone $(2.5 \mathrm{mM})$ was prepared in methanol. One $\mathrm{mL}$ of the stock solution of progesterone in a vial was mixed with each $1 \mathrm{~mL}$ of $\mathrm{HP}-\beta-C D$ or $\beta$-CD (2.5 mM) dissolved in water. The mixtures were stirred for $1 \mathrm{~h}$ at room temperature before ESI-MS analy'sis

The ESI-MS analysis. The ESI-MS experiments were performed with an API $4000^{\mathrm{TM}}$ triple quadrupole LC/MS/MS System (Applied Biosystems. Foster City. CA. USA) equipped with a turbo electrospray ion source. The sample solutions were directly infused into the ESI source with a flow rate of 10 $\mu \mathrm{min}^{-1}$. Spray voltage, declustering potential. and entrance potential were set to $4.5 \mathrm{keV} .120 \mathrm{eV}$. and $10 \mathrm{eV}$ in the positive ion mode. respectively. Pressures of curtain gas and ion source gas 1 were 10 and 17 psi., respectively.

Acknowledgments. This work is supported by KOSEF (2009-0059986) in 2008. SDG.

\section{References}

1. Buntner, B.; Nowak, M:- Kasperczyk, T; Ryba, M.; Grieb, P.; Walski. M: Dobransky. P.: Bero. M J. Controll Rel 1998. 56, 159.
2. Latha, M S.: Lal. A. V: Kumary, T. V.: Srekumar. R: Tayalirishnan, A. Contraception 2000, 61, 329.

3. Pitha, T. Phamacentical Preparations Containing Cyclodextmin Derivatives: United States Patent 4727064.

4. Torri, G.; Bertini, S;: Giavana, T; Guemini, M; Puppini, N.; Zoppetti. G. J. hel. Phenom. Hacro. Chent. 2007, 57, 317.

5. Zoppetti, G.; Puppini, N.; Pizzutti, M.; Fini, A.; Giovani, T.; Comini, S. J. Incl. Phenont Hacro. Chem 2007, 57, 283

6. Cerchiara, T.; Luppi, B.; Bigucci, F.: Zecehi, V. ht. J. Pham. 2003, 258, 209

7. Forgo, P: Göndos, G. Wonatsheffe fir Chemie Chemical Monthy 2002, 133,101

8. Connors, K. A. Chem. Rev 1997,97, 1325.

9. Attwood, J. L.; Davies, J. E. D.; MacNicol, D. D.; Vögtle, F. Comprehensine Supromolecular Chemistry: Cyclodetrins; Szejtly, T.: Osa, T., Eds; Elsevier Science: Oxford, 1996; vol. 3.

10. Moon, T.-W.; Lee, J. W.: Jhee, K.-H.; Khang, K.-W.: Jeong, H.-S.: Yang. S.-A.: Kin. H.-I. Bull Korean Chem. Soc. 2008. 29,1579

11. Báe, J-R.: Lee, C. Bull Korean Chem. Soc. $2009,30,145$.

12. Sweetman, S. C. Martindale: The Complete Drug Reference, $33^{\text {rd }}$ d.; Pharmaceutical Press: UK, 2002; p 1489

13. Irie, T: Uekama, K. J. Phom. Sci. 1997, 86, 147.

14. Irie, T.; Fukunaga, K.; Pitha, J. J. Phamt. Sci. 1992, 86, 147.

15. Electrospray Ionization Mass Spectrometr: Fundamentals, Instrumentation, and Applications; Cole, R. B., Ed; Wiley-Interscience: New York, 1997.

16. Bartlett, M. G.; Srinivasan, K. Rapid Commm Mass Spectrom. $2000,14,624$.

17. Przybylski, M.; Glocker, M. O. Angew: Chem. Int. Ed. Engl. $1996,35,806$.

18. Caballero, J.; Zamora, C; Aguayo, D.; Yaňez, C.; GonzálezNilo, F. D. J. Phus. Chem. B 2008, 112, 10194.

19. Rábara, L.: Aranyosiova, M.; Velic, D. Appl. Suf. Sci. 2006. 252.7000 .

20. He, P.; Lu, H.; Guo, Y. Anal Letr. 2003, 36, 493.

21. Kobetic, R.; Jursic, B. S.; Bonnette, S.; Tsai, J. S.-C.; Salvatore, S. J. Tefrohed won. Lett. 2001, 12,6077.

22. Lamcharfi, E; Chuilon, S.; Kerbal, A.; Kunesch, G.; Libot, F.; Virelizier, H. J. Mass Spectrom. 1996, 31, 982

23. Dotsikas, Y.: Loukas, Y. L. J. Pharm. Biomed Anal 2002. 29. 487.

24. Cunniff, I. B.; Vouro, P. J. Am. Soc. Mass Spectrom. 1995, 6 , 437.

25. Gabelica, V: Galic, N:- De Pauw E. J. Ant. Chem. Soc. Mass Spectront 2002, $13,946$.

26. Lee, S.; Ahn, S.; Park, S.; Oh, H. B. Int. J. Mass Spectront 2009, 279,47 